\title{
A Research on Curriculum of BTI from the Analysis of Students' Needs
}

\author{
Zhang Biyun \\ School of Foreign Languages \\ Yan'an University \\ Yan'an, China \\ 26282663@qq.com
}

\begin{abstract}
This research, in consideration of the status quo of translation education and its research in China, strives to study BTI curriculum in Yan'an University from the perspective of needs analysis, which is an efficient and indispensable step in curriculum design. To provide a greater insight into BTI curriculum in Yan'an University, a questionnaire has been conducted to investigate its problems. The results show that the existing BTI curriculum in Yan'an University could not completely meet the students' needs. Problems such as insufficiency of practice-oriented courses and language enhancement courses come out to be the most serious ones.
\end{abstract}

Keywords-BTI; curriculum; Yan'an University; Needing analysis

\section{INTRODUCTION}

Foreign language teaching in China has boasted a history of over one hundred years. However, how to educate translators still remains a disputable issue. From the 1990s, in the wake of development in politics, economy, culture, science and technology, professional translators are in great demand in China. Traditional translation teaching could not meet the requirements of the new circumstances any longer. The development of high technology and informationization would definitely bring about challenges in translation teaching.

The year 1997 marked the milestone of translation education. Translation teaching has developed from one or two courses in Foreign Language Departments into an independent department. The first Translation Department was established in Guangdong University of Foreign Studies, which intended to educate professional translators for foreign trade, economy and commerce as well as international communication.

From the outset of $21^{\text {st }}$ century, with the constant endeavor of an array of translators and administrators, translation teaching in China has undergone immense reform and development. In 2006, the Ministry of Education granted three universities BTI (Bachelor of Translation and Interpreting). They are Fudan University, Hebei Normal University and Guangdong University of Foreign Studies. This great event symbolizes that translation has become an independent discipline and a complete system of translation education from Bachelor to Doctor has shaped in China.

This research is supported by Social Science Fund Project of Yan'an University "Research on the Dubbing Translation of Movies and Cultural Communication" (YDK2015-34).
In 2015, BTI was granted by the Ministry of Education in Yan'an University. In 2016, the first students of translation specialty were enrolled at this university.

In light of this context, this research attempts to conduct a study on the existing BTI curriculum of Yan'an University, in the hope of providing enlightenment to the innovation of BTI curriculum and construction of translation teaching system at an undergraduate level.

\section{A BRIEF INTRODUCTION TO NEEDING ANALYSIS}

Due to different perspectives and situations, needs enjoy many definitions, either product-oriented or process-oriented.

Berwick provided a simple definition to needs. He called it gaps between "a current state of affairs" and "a desired future state" [1]. This definition is abstract and general. However, according to Robinson, an effective course develops from a needs analysis "aims to specify as closely as possible, what exactly students have to do through the medium of English" [2]. Widdowson defined needs as "learners' present study or future job requirements, in other words, what they have to be able to do at the end of their language course" [3]. And what is also product-oriented is Mountford's view, which holds that needs refer to "what the user-institution or society at large regards as necessary or desirable to be learnt from a program of language instruction" [4]. In comparison, process-oriented view focuses more on learners. Richterich remarked that the identification of language needs "consists primarily in compiling information both on the individuals or groups of individuals who are to learn a language and on the use which they are expected to make of it when they have learnt it" [5]. Likely, Kemp defined it as "a gap between what is expected and the existing conditions" [6].

Product-oriented or process-oriented, needs had always been defined in a relatively biased way by focusing on one aspect or stage of teaching, while teaching is a systematic process, involving many factors and participants. Therefore, Shu Dingfang suggested two main needs, namely, social needs and learners' needs. Social needs refer to needs of government and needs of social organizations, while learners' needs include objective and subjective needs. The objective information includes the present foreign language level, age, educational background, learning experience of learners, while 
subjective information refers to learners' preferable length and intensity of the course, learning goals and teaching methods.

The present study will analyze students' needs in the form of a questionnaire from the perspective of Shu Dingfang's needs analysis. Students' needs mainly concern students' educational background, language level, motivation, expectation, etc.

\section{RESEARCH DESIGN}

To provide a greater insight into BTI curriculum, in the present research, a questionnaire has been conducted to investigate problems in BTI curriculum of Yan'an University. There are altogether fifteen questions designed in the questionnaire to investigate the gaps between students' needs and the BTI curriculum.

\section{Q1: What is your current English level?}

Q2: (For those without any certificates, skip this question) What certificates regarding English have you got?

Q3: What is the most important factor affecting your choice of translation and interpretation for your bachelor's degree?

Q4: In your opinion, compared to other English specialties, what are the advantages of translation specialty?

\section{Q5: How much do you know about BTI?}

Q6: Are you satisfied with the courses offered by the translation department of our university?

Q7: Which courses are most helpful? Why?

Q8: How often do you carry out translation practice (including translation and interpretation)?

Q9: To what extent does the existing BTI curriculum help you to carry out translation practice?

Q10: Are you optimistic about the employment situation of BTI graduates?

\section{Q11: What is your ideal career?}

Q12: (For those who are not intended to engage in translation, skip this question) If you are intend to be engaged in translation, what of the following would you choose?

Q13: Do you think BTI graduates have greater advantages in doing translation work?

Q14: Do you want to get some translation training at present? What are they? university?

Q15: What are your suggestions to BTI curriculum of our

\section{A. Participants}

The participants of the research consist of 30 BTI freshmen and 30 BTI sophomores of Yan'an University. By the time when the study was carried out, all the freshmen have finished the first-year courses offered by the translation department of Yan'an University and all of the 60 students have been acquainted by the department with BTI teaching syllabus so that they are qualified to give assessment and suggestions to the curriculum.

\section{B. Instruments}

The questionnaire is composed of three parts. The first part is about education background of the participants, the second part tries to reflect attitudes of the participants towards the existing curriculum, as well as gaps between their expectation and the curriculum. The third part of the questionnaire is about their job plan after graduation.

Twenty-eight freshmen and twenty-nine sophomores among 60 participants have responded the questionnaire. That is, $95 \%$ questionnaires have been completed, which indicates that data from these questionnaires are reasonable and scientific to draw the conclusion.

\section{Research Questions}

The questionnaire contains 15 questions to investigate the gaps between students' needs and BTI curriculum of Yan'an University. Two of them are open questions while others are multiple choices, depending on the purposes of the questionnaire. For the complete questionnaire, see Appendix.

\section{PROBLEM EXPLORATION}

To develop an efficient curriculum, we have to select key components, proper materials, relevant tasks and activities, which will help to realize teaching objectives. The selection should be based on the learning of students' demand. Only when schools, language courses or teachers have a clear idea on students' characters, education background, interests, strong and weak points as well as actual needs can they succeed in teaching [7].

The information of the participants provided and analyzed in this part could fall into two categories, objective and subjective information. Objective information here refers to students' educational background, translation experience and subjective information includes motivation, expectation on BTI curriculum, and feedback on the courses on offer etc.

\section{A. Objective Needs}

In regard to education background, none of the students have acquired any certificates in English or translation.

As to translation experience, 36 of all the 57 participants $(63 \%)$ believed that they had a little experience in translation, 21 of them $(37 \%)$ claimed that they had never engaged in any translation practice, and none of them had much translation experience.

Objective needs indicate that in order to improve the students' translation proficiency, BTI curriculum should take much responsibility, if not all.

\section{B. Subjective Needs}

Regarding why they choose translation and interpretation for their bachelor's degree, 27 participants said that they choose it for better job prospects, accounting for $47 \%, 18$ choose it out of love and interest, accounting for $32 \%$, and 7 of them choose it because of their parents' requirements, accounting for $12 \%$. The other 5 choose it because there is no better alternative, accounting for $9 \%$. 
What is practical is that nearly half of the students hope that undergraduate study could enable them to hunt better jobs after graduation.

\section{Tentative solutions}

For the participants are all translation students, most of them wished to have an improvement in translation and interpretation competence, which is their major purpose of undergraduate study. Therefore, 49 of the 57 participants $(86 \%)$ hoped to take enough practice-oriented courses. Some students give some very detailed expectations, such as offering some specialized translation courses and translation-related courses.

What should be paid much attention is that, only 3 students expect to have a language competence enhancement. This does not mean they are qualified enough in doing translation. Since the existing curriculum has not offered courses aiming to improve students' language proficiency, when they answered this question, they forgot this competence.

In all the six required courses offered for the translation students, four of them are comparatively satisfying, namely, E-C translation, C-E translation, Comparative Study of English and Chinese and translation as well as interpretation. An Introduction to Translation and Chinese and Western Translation History are not so satisfying.

Though practical translation courses are popular with students, over $90 \%$ of the participants, think that the content of these courses is inappropriate for there is too much literary translation but little practical or specialized translation and most teaching materials are outdated, which are far from meeting social demand. Moreover, translation of specialized sectors or styles covered in these courses is too general to be mastered by students for limited teaching hours.

Among the undergraduates, about $60 \%$ admit that the existing curriculum enables them to realize some of their primary goals while about $34 \%$ consider that it helped very little, solely 2 of them are sure that the curriculum helped them a lot, accounting for only $3 \%$ of the total.

Referring to the conclusion drawn from the surveys of this study, the following courses will be suggested to open for translation students.

First, language enhancement courses of both English and Chinese are a must for students of translation. Courses like Advanced English, Chinese Writing or Selected Readings on Chinese and English Literature could be offered. Translation is a comprehensive discipline, and students of English, as the results show previously, are usually short of encyclopedic knowledge, so preparatory courses like Linguistics, Business, commerce etc. should be introduced. Preparatory courses should coincide with the specialized courses.
Of course, specialized translation courses should be offered as well for they could greatly improve students' translation competence. Courses such as Translation of Legal \& Political Texts, Translation of Economic \& Commercial Texts, Consecutive Interpretation of Scientific and Technical Texts etc. could be included in BTI curriculum.

Other practice-oriented courses like general translation and interpreting should also be an indispensable part in BTI curriculum. Computer-aided courses must be supplied to students which could greatly accelerate translation speed and efficiency. Apart from practice-oriented courses, theoretical courses on translation are also important for BTI students.

\section{CONCLUSION}

The present research has detected lots of problems in BTI curriculum of Yan'an University.

First, practice-oriented, especially specialized translation courses display great blanks in BTI curriculum of Yan'an University. Second, language enhancement courses are also urgently needed.

Therefore, the present study suggests that in curriculum design, we should strive to seek a better balance between three pairs of contradictions - theoretical courses and practice-oriented courses; translation training and language training as well as translation competence improvement and students' cognitive process.

\section{ACKNOWLEDGMENT}

This research is supported by Social Science Fund Project of Yan'an University "Research on the Dubbing Translation of Movies and Cultural Communication" (YDK2015-34).

\section{REFERENCES}

[1] R. Berwick, Needs Assessment in Language Programming: from Theory to Practice. In Johnson, R. K(ed). The second language curriculm. Cambridge: Cambridge University Press, 1989, p. 52.

[2] P. Robinson, ESP today. London: Prentice Hall International Itd. 1991, p 3.

[3] H. Winddowson, Teaching Language as Communication. Oxford: Oxford University Press, 1978, p. 2.

[4] A. Mountford, The What, the Why and the Way. London: London Group, 1981, p. 27.

[5] R. Richterich, Case Studies in Identifying Language Needs. Oxford: Pergamon Press, 1983, p. 55.

[6] J. Kemp. Designing Effective Instruction. London: Prentice Hall Press, 1998, p. 21.

[7] Shu Dingfang, FIT in China, Problems and Suggested Solutions. Shanghai: Shanghai Foreign Language Education Press , 2004, p. 68. 